\title{
Una lectura de El Llano en llamas desde Corea: el valor social de la facultad emotiva
}

DOI: $10.32870 /$ mycp.v3i8.466

Hwayong Shin ${ }^{1}$

\section{Resumen}

En este artículo se explora el rol positivo de las emociones para prevenir estados de crisis que podrían provocar la demolición de una sociedad, a través del análisis sociopolítico y simbólico del cuento El Llano en llamas de Juan Rulfo. En contra de los estudios anteriores que habían evaluado negativamente la influencia de la emoción sobre la estabilidad social, estudios recientes de disciplinas como la ciencia política o la neurociencia han revelado que la capacidad de las personas de sentir emociones puede contribuir a la sociedad mediante el fomento de la atención, la cooperación y la ansiedad sobre los fenómenos sociales. Al examinar cómo el cese de dicha capacidad emotiva en la gente deriva en la circulación de tragedias, en este artículo se confirma que la facultad emotiva puede coadyuvar a la estabilidad de la sociedad y se muestra que la emoción puede generar mayor conciencia social.

Palabras clave: facultad emotiva, fenómenos políticos, crisis social, análisis simbólico y sociohistórico, Juan Rulfo.

Artículo recibido el 15 de enero de 2014 y dictaminado el 13 de febrero de 2014.

1. Estudiante de posgrado en Ciencias Políticas, Universidad Nacional de Seúl. Correo electrónico: hwayongshin@snu.ac.kr 


\title{
A STUDY OF EL LLANO EN LLAMAS FROM KOREA: THE SOCIAL VALUE OF THE ABILITY TO FEEL EMOTIONS
}

\begin{abstract}
This article explores the positive role of emotions in preventing conditions of crisis that might result in the demolition of a society, through the sociopolitical and symbolic analysis of Juan Rulfo's short story El Llano en llamas. Contrary to previous studies with negative evaluations of the influence of emotions on social stability, recent studies from academic fields such as political science or neuroscience reveal that people's ability to feel emotions can contribute to society by fostering attention, cooperation, and anxiety about social phenomena. By examining how the cessation of people's ability to feel emotions results in the circulation of tragedies, this article reaffirms that people's ability to feel emotions can contribute to social stability and shows that emotions can provoke conscious thought and care for society.

Keywords: role of emotions, political phenomena, social crisis, symbolic and socio-historical analysis, Juan Rulfo.
\end{abstract}

\section{Introducción}

En los últimos años, las investigaciones sobre el factor de la emoción en la política han ocupado uno de los primeros planos. Desde los aportes de la neurociencia social, en donde destacan las propuestas teóricas en torno al papel de la emoción de Joseph E. LeDoux (The Emotional Brain: The Mysterious Underpinnings of Emotional Life, 1996) y de Antonio C. R. Damásio (The Feeling of what Happens: Body and Emotion in the Making of Consciousness, 1999), hasta los estudios de neuropsicología de Edmund T. Rolls (The Brain and Emotion, 1999) y, más recientemente, de Drew Westen (The Political Brain: The Role of Emotion in Deciding the Fate of the Nation, 2008), han ido restando autoridad al tradicional tratamiento del sentir y el pensar como conceptos independientes y hasta antagónicos. En este artículo destacaremos en especial la investigación del politólogo estadounidense George E. Marcus, expuesta en The Sentimental Citizen: Emotion in Democratic Politics (2002), libro que se ha convertido en un clásico del área, donde aplica los conocimientos de los sistemas emotivos del cerebro para estudiar y justificar los hábitos y las reacciones políticas de los ciudadanos, como el mismo autor anuncia con modestia en su prólogo: 
"La meta de este libro es proponer la opinión poco probable de que la solución para la buena ciudadanía radica en nuestra capacidad de sentir" (Marcus, 2002: 8). ${ }^{2}$

La facultad emotiva podría definirse en los siguientes términos: "Proceso emocional que conlleva la capacidad de acoplar o de repeler la dependencia de un hábito. Cuando los procesos emocionales rechazan un uso habitual, lo hacen con apoyo en la razón y en un estado atento de la mente" (Marcus, 2002: 138). La contribución de dicha facultad emotiva a la estabilidad de una sociedad había permanecido prácticamente sin reconocimiento. Sin embargo, la facultad de la gente de sentir felicidad o tristeza y de simpatizar con los demás o con alguna causa es un elemento invaluable para evitar la fractura y hasta la demolición de una sociedad dada.

La tragedia que conlleva la desaparición del sentido de solidaridad entre los miembros de un grupo debido al cese de la facultad emotiva, está bien representada en el cuento El Llano en llamas, del reconocido escritor mexicano Juan Rulfo. Los personajes revolucionarios en este relato llegan a un punto tal de no sentir ninguna emoción ante el dolor y la aflicción de los soldados de la tropa de gobierno, de sus compañeros y hasta de sus propias familias. En consecuencia, el cese de la facultad emotiva elimina

2. Las traducciones provenientes de textos originalmente en inglés son propias.
La tragedia que conlleva la desaparición del sentido de solidaridad entre los miembros de un grupo debido al cese de la facultad emotiva, está bien representada en el cuento El Llano en llamas, del reconocido escritor mexicano Juan Rulfo. Los personajes revolucionarios en este relato llegan a un punto tal de no sentir ninguna emoción ante el dolor y la aflicción de los soldados de la tropa de gobierno, de sus compañeros y hasta de sus propias familias. En consecuencia, el cese de la facultad emotiva elimina la posibilidad de reconciliación, de cooperación y responsabilidad social de la gente 
la posibilidad de reconciliación, de cooperación y responsabilidad social de la gente, según trataremos de mostrar en este artículo.

En los apartados siguientes examinaremos las teorías de las perspectivas negativa y positiva de la función social de la emoción. Entre ambas proposiciones, aplicaremos la perspectiva positiva del rol social de la emoción, justificándola con los indicios y las estrategias discursivas de El Llano en llamas. Revisaremos primero los índices que representan la desaparición de la función social de la emoción en el cuento, como el uso del vocabulario que se utiliza para describir animales, el orden de aparición de dichos animales en el orden del relato: pájaros, coyotes y toros, que simbólicamente marcan el proceso de pérdida de la facultad emotiva entre los miembros de la sociedad, así como la intensificación concomitante de violencia y tragedia en la sociedad. En un segundo momento mostraremos que el cese de la facultad emotiva conlleva la circulación de la tragedia en el nivel no sólo de familia, sino también de la sociedad. Desde el análisis de El Llano en llamas, centrando la atención en la parálisis de la facultad de sentir, podremos determinar el rol y el valor social de la facultad emotiva como elemento esencial y origen de la solidaridad, cooperación y responsabilidad entre la gente, y de la estabilidad y la voluntad para mejorar su sociedad.

\section{La experiencia de leer a Juan Rulfo en Corea}

El cuento más extenso y que da su nombre al volumen, El Llano en llamas, se ha traducido a más de 40 idiomas, pero aún está pendiente su versión en coreano (Macías, 2013: 212). ${ }^{3}$ Entre los problemas a los que nos enfrentamos los lectores extranjeros leyendo las obras de Juan Rulfo, están el insuficiente conocimiento del contexto histórico de los cuentos, el dominio imperfecto del español para entender el sentido y la riqueza que hay en la obra de Rulfo. A pesar de esos obstáculos y aunque El Llano en llamas trata de la historia de

3. El volumen llegó a nuestras manos gracias al Seminario de Textos Clásicos de la Facultad de Humanidades, de la Universidad Nacional de Seúl, donde los estudiantes próximos a graduarse tienen la oportunidad de entrar en contacto con los clásicos en sus idiomas originales. Y en nuestro caso particular, no obstante pertenecer al posgrado en Ciencias Políticas, el interés por el español y la cultura hispanoamericana nos llevó a sumarnos a dicho grupo en el semestre de primavera de 2013, al saber que se estudiaría un texto sobre la Revolución Mexicana de un importante escritor mexicano, como homenaje en los 60 años de la publicación de El llano en llamas. 
México con contextos muy regionales de Jalisco, es impresionante su valor artístico en Corea también.

El Llano en llamas es significativo para los lectores coreanos, en especial desde dos perspectivas. Primera, el cuento trata del conflicto interno de un país. Corea, país dividido en dos partes hasta ahora ya por más de medio siglo, es una región que se ha constituido como un símbolo del conflicto interno de una nación. Desde la narración de El Llano en llamas, se puede inferir cómo fueron los hechos durante la guerra civil. Además, podemos presumir las causas que llevaron a la gente a ser incapaz de cuidar de sus connacionales y cómo pudieron llegar a ser totalmente indiferentes ante los del otro lado. Aunque es doloroso reavivar heridas del pasado trágico, el esfuerzo para recordar las lecciones desde la historia es necesario y El Llano en llamas puede ayudar a los lectores a recordar las lecciones correspondientes de la historia del conflicto interno en Corea también, para evitar o tratar de buscar solución a la tragedia del pasado que pervive hoy en día.

Segunda, el conocimiento de un relato de otro país, México en este caso, nos permite acceder a la lección sociopolítica universal que puede ser aplicada en México, como espacio del cuento, a Corea, el lugar de los lectores coreanos, y hasta prácticamente todos los países del mundo. La lección sociopolítica ejemplar del cuento es que la desaparición de la facultad emotiva de los miembros de una sociedad puede agravar el conflicto interno y dejar las semillas que provocarán otras tragedias sociales. Ya que los vestigios de los conflictos internos del pasado se encuentran en la Corea contemporánea también, podemos estar de acuerdo más fácilmente con el mensaje cifrado en El Llano en llamas. Desde este punto, podríamos empezar a considerar los casos de otros países, reconociendo el valor de los estudios comparados.

Por otra parte, la lectura de El Llano en llamas es importante también en el ámbito de las ciencias sociales, incluso de las ciencias políticas. El entendimiento de los fenómenos políticos se puede conseguir a través no sólo de los artículos que directamente tratan sobre las investigaciones de las ciencias políticas, sino también de acercarse a la literatura, llena de la imaginación de los autores, sí, pero que no pocas veces complementa los vacíos de la historia. Para entender bien la historia, la sociedad y los motivadores políticos de la gente, la facultad de la empatía, que implica entrar en las mentes y las situaciones de otras personas, es un valor precioso que requiere un alto nivel de imaginación, similar al de los novelistas (Berlin, 1979: 105-108). 
Podemos entrar en la mente y en la vida de un revolucionario ordinario cuando leemos El Llano en llamas, y quedaremos sorprendidos por su actitud completamente indiferente ante la demolición de la sociedad y la tragedia de los demás. Desde esa experiencia de vida de un revolucionario, podremos comprender el valor social de la capacidad de sentir. Especialmente, como casi todos los personajes del cuento El Llano en llamas tienen su referente histórico y la fábula está concentrada en su carácter sociohistórico (Macías, 2013: 213), la lectura de este cuento, además de ser mucho más viva y realista, pone en juego implicaciones que permiten entender los fenómenos sociales y la vida de la gente ordinaria durante este tipo de movimientos sociales.

\section{El cese de la facultad emotiva y la tragedia concomitante de la sociedad}

La emoción se ha considerado con frecuencia como la causa del desorden en los fenómenos políticos, ya que disuade a la gente de tomar decisiones racionales. Sin embargo, en contraste con esta noción popular, el uso de la emoción es necesario en la política con el fin de inducir a la gente a sentir y a preocuparse por los demás, a pensar y cuidar de la sociedad. La tragedia causada por el cese del rol de la emoción en la sociedad está bien representada en el cuento El Llano en llamas (1953), en el cual Rulfo recrea el mundo de los revolucionarios durante la Revolución Mexicana.

Juan Rulfo nació en la región de Jalisco en 1918, cuando la Revolución Mexicana había prácticamente terminado. Pero Rulfo vive la experiencia de la Guerra Cristera que empezó en parte como reacción a los resultados de la Revolución Mexicana. Durante estos periodos de revoluciones y guerras, Juan Rulfo perdió a sus padres. La presencia de la violencia en el Llano Grande de Jalisco marcó una fuerte influencia en la escritura de Rulfo, como lo ha señalado ampliamente la crítica. La tragedia ocurrida en el gran Llano de Jalisco quedó plasmada en el libro de cuentos El Llano en llamas, en el que los cuentos dibujan las vidas devastadas de los pueblos bajos debido a la violencia que aparece representada en las llamas del título.

Entre los cuentos de Rulfo, El Llano en llamas, obra que tiene el mismo título que la colección, narra la experiencia de un campesino que participó en una tropa de revolucionarios bajo el mando de Pedro Zamora. El narrador no expresa ningún sentimiento ni juicio sobre la crueldad o los hechos inmorales. Especialmente, la circulación de la tragedia que resulta de la incapacidad de 
sentir está bien expresada en el corrido popular que aparece en el inicio del cuento:

"Ya mataron a la perra, pero quedaron los perritos..."

Esta frase, que "la perra murió, pero los perritos quedaron", insinúa que la obra tiene varias implicaciones más allá de la narración superficial. Ante todo, siguiendo la ilación del corrido original, la frase del epígrafe significa la voluntad firme de los revolucionarios en la lucha (Mendoza, 1954: 78-80). Sin embargo, si el sentido del epígrafe se extiende a un significado general, esta frase se puede interpretar como alusión a la circulación de la tragedia que se repite de generación en generación. Las claves de la generalización del significado de las frases y la propuesta de interpretación de "la repetición de la tragedia" serán tratadas con detalle en los siguientes apartados. Los indicios del corrido en el prólogo muestran que el rol de la emoción en los fenómenos políticos es importante para evitar la circulación de la tragedia.

\section{El rol de la emoción, perspectiva negativa: evasión de su uso en la política}

Desde la perspectiva negativa sobre el rol de la emoción en los fenómenos políticos, se considera que la gente debe determinar y escoger sus opiniones de manera razonada sobre dichos fenómenos políticos y no desde su emoción, a fin de establecer una sociedad tranquila y para alcanzar decisiones justas. En esta perspectiva se recomienda evitar la influencia de la emoción porque, primero, la emoción surge de motivos ocultos e inciertos; segundo, la emoción provoca actos o debate público sin deliberación y, tercero, la emoción, debido a su parcialidad, impide la plena consideración de la opinión alternativa. ${ }^{4}$ Ade-

4. La cita textual en inglés dice: "First, emotions arises from hidden and uncertain causes [...] Second, emotions are thought to provoke action without thought, both individually and collectively [...] Third, emotion is presumed to diminish a full consideration of the intended action" (Marcus, 2002: 21 y 22). En esta parte, Marcus resume la evaluación convencional sobre emoción que refutará en las páginas siguientes. Este tipo de percepción sobre la emoción supone que emoción y razón son elementos contrarios. Diferente a la evaluación negativa, observaremos que emoción y razón están interrelacionadas en los comportamientos de la gente en una sociedad. 
más, otras teorías consideran la emoción, por ejemplo la "compasión", como una fuerza irracional que puede engañar o distraer cuando se piensa sobre la política social y como una causa para basar el juicio político sobre una fuerza que es afectiva e instintiva, en lugar de cognitiva o reflexiva. ${ }^{5}$

Algunos filósofos sociales pensaban que la influencia de la emoción tenía que reprimirse para evitar desórdenes y conflictos en la sociedad. En esta línea, los investigadores consideraban que el uso de la emoción tenía que ser controlada o reprimida porque dañaba la tranquilidad, la disciplina y la justicia de la sociedad. ${ }^{6}$ Se puede encontrar este tipo de pensamiento en las teorías de Platón y en las opiniones de los fundadores de Estados Unidos de América. Platón opinaba que la naturaleza humana se organiza jerárquicamente en la razón, la emoción y las necesidades corporales, y entre los tres componentes, dando prioridad a la razón como preferencia normativa y clara (Valentino, Hutchings, Banks, y Davis, 2008: 249). Por ello, según Platón cuando la razón choca con la pasión, la pasión tiene que retroceder. ${ }^{7}$ Los llamados Padres Fundadores, redactores de la Constitución de Estados Unidos, pensaron que sólo

5. “Algunas teorías modernas sobre la moral — teorías morales liberales e individualistas, en particular - han tratado la compasión como una fuerza irracional en lo referente a los asuntos humanos, ya que es susceptible de engañarnos o de distraernos cuando estamos tratando de razonar sobre política social [...] La simple oposición entre emoción y razón también ha sido invocada por los críticos del liberalismo comunitario, quienes han sugerido que si se le da espacio a un sentimiento como la compasión, que no parece tener mucho prestigio en la teoría liberal, esto significaría sentar las bases del juicio político sobre una fuerza afectiva e instintiva, en lugar de una cognitiva que deliberaría con base en la razón y el pensamiento" (Nussbaum, 1996: 28). En esta parte, la filósofa critica las teorías con pensamiento dicotómico entre la razón y la emoción. Después, en este artículo muestra que la emoción, especialmente la compasión, es un tipo de razonamiento.

6. “Generaciones a favor del pensamiento político y de la investigación sobre el proceso de la formación de opinión y la decisión política se han centrado en la cognición y en el papel trivial de la emoción, que a menudo se considera como un componente pernicioso de la política, la cual tendría que ser controlada y evitada para proteger la estabilidad política, la tolerancia y la justicia (como argumentaron, por ejemplo, los redactores de la Constitución de Estados Unidos)" (Jacobs y Shapiro 2011: 14 y 15). Esta línea de investigación considera que la emoción causa tumultos sociales y el cese del pensamiento juicioso y discreto.

7. “La concepción de Platón sobre la naturaleza humana está organizada jerárquicamente empezando por la razón, seguida de la emoción y de las necesidades básicas corporales incluyendo los apetitos, con una clara preferencia normativa de la primera sobre las dos últimas" (Valentino, et al., 2008: 249). Westen agrega sobre el particular: "Los redactores de la Constitución de Estados Unidos [...], acordes con más de 2,000 años de filosofía occidental desde Platón, temían la influencia distorsionante de la emoción sobre el pensamiento racional necesario para tomar buenas decisiones en una democracia. Platón sostenía que cuando la razón y la pasión chocaban entre sí, el lugar apropiado de la pasión estaba en el asiento trasero" (2008: 26). 
la razón pudo hacer que la gente frenara sus deseos "egoístas y parroquiales" para tomar decisiones de interés común (Westen 2008: 26).

Esas perspectivas consideran que el uso de la emoción debe ser un objeto de vigilancia debido a su peligrosa influencia en la sociedad. La emoción, cuando se utiliza mal, puede causar desastres sociales, como conflictos internos o toma de decisiones imprudentes e impetuosas. A diferencia de esta perspectiva, en El Llano en llamas la gente que carece de emoción pierde su facultad de pensamiento consciente, lo que muestra que la supresión, y no la incitación del rol social de la emoción, es más pernicioso para la estabilidad social.

\section{Perspectiva positiva: rol conductivo de la emoción en la política}

Aunque la perspectiva negativa que se preocupaba de los riesgos potenciales del uso de la emoción era más clásica en el estudio de la política y más popular en el sentido común, la opinión contraria apareció con la defensa para el rol de la emoción en los fenómenos políticos. La perspectiva positiva considera que el uso de la emoción es necesario para una sociedad activa y armónica. Contrario a las opiniones previas, investigadores sociales y politólogos descubrieron que la emoción es un motivador de la acción política como atención y deliberación sobre los fenómenos sociales. Además, comprobaron que la gente comienza a usar la razón en sus pensamientos bajo iniciativa y dirección del proceso emocional (Marcus, 2002: 136). Para crear un espacio público en la sociedad democrática que permita la decisión colectiva entre visiones opuestas, la política debe ser emocional, pues sólo como seres emocionales serán los ciudadanos capaces de participar en la razón y dejar de lado la contraria y cómoda dependencia sobre hábitos que podrían impedir el progreso (Marcus, 2002: 147 y 148).

Este punto de vista está apoyado por las investigaciones del evolucionismo y la psicología sobre el rol de la emoción. Charles Darwin pensó que las emociones tenían una función adaptativa para comunicar su intención y sus necesidades a través de una señal emocional, y que la emoción era una de las fuentes más potentes de la motivación que impulsaba las acciones humanas (Westen, 2008: 70). Sigmund Freud, por su parte, también señaló que las emociones pueden servir como motivadores de metas múltiples, permitiéndonos fijar una significación motivacional a casi cualquier cosa. ${ }^{8}$

8. La cita en inglés señala: "What emotions can do that drives can't is to serve as multipurpose motivators, allowing us to attach motivational significance to almost anything" (Westen, 2007: 
Como Darwin y Freud, hay investigadores en la política que notaron que la emoción es un motivador de las acciones humanas. Según estos investigadores, la emoción es útil para aumentar la atención hacia los fenómenos sociales y la voluntad de participar en los discursos públicos. Por ejemplo, la emoción de la "ansiedad" fomenta el aprendizaje apropiado para las necesidades de la ciudadanía, porque la persona aprensiva presta mayor atención a las circunstancias políticas, y la emoción del "entusiasmo" aumenta la participación en los eventos sociales, como en las campañas electorales por ejemplo (Marcus y MacKuen, 1993: 680 y 681). Especialmente, la emoción de la "ansiedad" conduce a la gente a participar de una mentalidad consciente y a pensar nuevas posibilidades, en lugar de estar dependiendo de los hábitos (Marcus, 2002: 96 y 97). Además la facultad emotiva fomenta en los ciudadanos, no sólo en las acciones privadas sino también en las acciones públicas, a seguir la deliberación y el consenso públicos y, finalmente, la emoción les permite sobreponer los resultados del entendimiento a la acción (Marcus, 2002: 148).

La perspectiva positiva sobre el rol de la emoción considera que el proceso emocional anima a la gente a tener atención o aprehensión respecto a las situaciones sociales, y a considerar las opiniones alternativas que le significan la simpatía o el esfuerzo para entender a los otros. Por ejemplo, como afirma Nussbaum, la emoción de la "compasión" está considerada como un tipo de razonamiento que conduce a la gente a considerar el bienestar de los demás y a pensar desde el interés de los otros. De esta manera, la "compasión" funciona como un puente entre la sociedad y el individuo. ${ }^{9}$ Como la emoción es un factor motivador e iniciador de la atención y deliberación sobre la comunidad y la sociedad, el cese de la facultad emotiva puede derivar en la demolición de una sociedad, de las vidas individuales y en una tragedia política como la representada en el cuento El Llano en llamas.

81). Según Freud, la emoción, a diferencia del instinto, instiga a la gente a empezar a actuar.

9. "En la tradición filosófica, la compasión es un puente fundamental entre el individuo y la comunidad; la compasión se concibe como una manera propia de nuestra especie para enlazar los intereses sobre los demás a nuestro propio provecho personal [...] La compasión es, sobre todo, un cierto tipo de pensamiento sobre el bienestar de los demás" (Nussbaum, 1996: 28). Como se afirma aquí, la capacidad de sentir compasión hacia los demás conecta a los individuos a su comunidad. Además, en este sentido la facultad emotiva de compadecerse es una facultad racional y consciente, no es una fuerza irracional. 


\section{Indicios de la supresión de "sentir" en El Llano en llamas}

El Llano en llamas no trata ya de la crónica vivida del momento revolucionario, sino de la reflexión del narrador-personaje que ve los hechos con varios años de distancia (Macías, 2013: 220). En este cuento la identidad del narrador es débil, sin voluntad ni pensamiento independiente. El narrador se refiere a sí mismo como "nosotros" a lo largo del cuento, como signo de la gente que no tiene el carácter de individuo. La gente de Pedro Zamora no tienen voz como seres humanos individuales y, además, ellos muestran muchos aspectos en que parecen animales, como sus nombres (la Perra, el Pichón). No hablan mucho, pero ven y huelen para vigilar, también como animales. En otras palabras, los hombres en el cuento muestran una actitud indiferente ante la situación de violencia, lo que significa que han perdido la capacidad de sentir. Si consideramos las teorías antes referidas, el cese de la facultad emotiva lleva a los hombres a la pérdida de pensamientos y juicios independientes en el cuento.

Con base en la pérdida de la capacidad de sentir y, consecuentemente, de la capacidad de pensar de los personajes, el primer sujeto del cuento no es una persona específica, sino que es "el grito"; el segundo sujeto es "el viento", y el tercer sujeto es "otro grito" (Rulfo, 1953: 69). ${ }^{10}$ Además, en el principio del cuento aparecen los símiles que comparan a la gente con animales para insinuar los caracteres animalizados de los personajes. Por ejemplo, los revolucionarios estaban "tirados panza arriba, como iguanas calentándose al sol" (p. 70), habían "subido [...] a gatas, como tejones espantados por la lumbre" (p. 72).

Junto con estos símiles, aparece vocabulario que se usa para describir a los animales al relatar los hechos de los hombres en el cuento. Por ejemplo, los revolucionarios mataron a la tropa del gobierno de manera de "hacerles pegar tamaño respingo de la vida a la muerte sin que apenas se dieran cuenta" (p. 71), en donde la palabra "respingo", derivada del verbo "respingar", corresponde a la reacción de "una bestia: Sacudirse y gruñir porque le lastima o molesta algo o le hace cosquillas" (s. v. DRAE). Esta manera de usar vocabulario propio de animales para la gente, significaría que el narrador no tiene ninguna emoción humana frente a la vida trágica de los otros ni ante la tragedia de la sociedad. La descripción de los muertos es igualmente muy cruel e indiferente. Sin ninguna emoción, como aprehensión, entusiasmo o compasión, los personajes

10. Cito por esta edición y, en adelante, solamente se indicarán las páginas entre paréntesis. 
no tienen interés alguno por los fenómenos sociales ni reflexionan en cómo resolver sus problemas sociales ni cómo mejorar la vida de sus familias y de otros en general.

La secuencia de la aparición de los animales dentro del cuento insinúa el proceso de parálisis de la facultad emocional; junto con la mentalidad que se degrada, se aprecia la intensificación de la crueldad e indiferencia de los hombres. En el inicio, cuando suena un tiro y empieza la descarga y la corretiza, aparecen los pájaros como "totochilos" (p. 70), "tordos" (p. 72) y "tildíos" (p. 73). Después de una serie de descargas, se oyen los aullidos de los coyotes de vez en cuando (p. 73), y después presencian los muertos apilados mientras los coyotes siguen aullando toda la noche (p. 74).

En la secuencia siguiente, debido al fuerte poder de los federales, la tropa de Pedro Zamora se separa y el narrador, el Pichón, pasa un tiempo escondido. Tiempo después, Zamora trata de reunir a su tropa y aparece la imagen de "destazar una vaca" y el sonido del "bramido de un toro" (p. 76), significando la transición a un ambiente más agresivo y peligroso. Con Pedro Zamora, los revolucionarios queman el llano y juegan a los toros. La parte del juego del toro muestra el más inhumano aspecto de los revolucionarios. En el juego del toro, Pedro Zamora con verduguillos no mata toros sino a hombres, ocho soldados del gobierno, el administrador y el caporal de la hacienda (p. 80). En esta escena los espectadores que aparecen denominados como "nosotros" no muestran ningún sentimiento ante la crueldad extrema del líder. Los del grupo, "nosotros", también son culpables porque no dejan salir a los toreros, solamente observan y cuelgan finalmente al caporal (pp. 80 y 81), lo que significaría que a estas alturas del relato, ellos ya eran insensibles al dolor de las víctimas.

Esta secuencia de la aparición de los animales muestra que los hombres han perdido la capacidad de sentir, aunque la situación se haya ido agravando más con el proceso de los incidentes. Primero, los pájaros reaccionan ante la violencia humana. Por ejemplo, los disparos de un tiro o una bala hacen volar a los totochilos y a los tildíos (pp. 70 y 73). Los coyotes también muestran su tristeza hacia la tragedia humana a través de sus aullidos. Aunque los coyotes no aparecen enfrente de la gente, son animales más violentos que los pájaros y se insinúa que los hombres estaban transformándose en un grupo más violento y cruel.

El siguiente animal, el toro, significa que los hombres han cambiado, ya que ahora su grupo no muestra ningún sentimiento ni reacción frente a 
la violencia o los dolores de otros y de la sociedad. Los toros en el relato no demuestran ninguna reacción emocional, a diferencia de los pájaros y los coyotes. Los toros aparecen en el cuento cuando los hombres hacen actos violentos, como destazarlos o quitarles el pellejo (pp. 76 y 78). En el extremo, Pedro Zamora juega como un toro, lo que significa que los hombres de la tropa de Pedro Zamora han perdido totalmente su capacidad de sentir emociones como inquietud, ansiedad, compasión, tristeza o terror ante la destrucción de las vidas de otros y de la sociedad. La consecuencia es terrible. Los hombres con Pedro Zamora roban o queman alimentos y ganado, matan a campesinos inocentes y violan a las mujeres sin sentir ninguna sensación o sentimiento de culpabilidad ni inquietud.

\section{Cuadro 1}

Correlación entre animales y hombres

\begin{tabular}{|c|c|c|c|}
\hline & TIEMPO 1 & TIEMPO 2 & TIEMPO 3 \\
\hline \multicolumn{4}{|c|}{ Animales } \\
\hline Típo & Pájaros & Coyotes & Toros \\
\hline Reacción frente a la violencia & Volar $(70,73)$ & Aullar $(73,74)$ & Ninguno \\
\hline Nivel de violencia & Bajo & Medio & Alto \\
\hline Capacidad de sentir & Débil & Medio & Nulo \\
\hline \multicolumn{4}{|c|}{ Hombres } \\
\hline Conducta & $\begin{array}{l}\text { Oler, oir }(70) \\
\text { Tirados panza arriba }(70) \\
\text { Subir a gatas }(72) \\
\text { Quedar agazapados }(72) \\
\text { Corretiza }(72)\end{array}$ & $\begin{array}{l}\text { Descubrir pilas } \\
\text { de muertos }(74) \\
\text { No encontrar } \\
\text { a la Perra }(74)\end{array}$ & $\begin{array}{l}\text { Destazar toros }(70) \\
\text { Despellejar toros }(72) \\
\text { Incendiar }(76,77,79) \\
\text { Asolar al pueblo }(79) \\
\text { Juego del toro }(80,81) \\
\text { Descarrilamiento }(82,83) \\
\text { Robar mujeres }(86)\end{array}$ \\
\hline Nivel de violencia & Bajo & Medio & Alto \\
\hline Capacidad de sentir & Débil & Débil & Nulo \\
\hline
\end{tabular}

Fuente: elaboración propia.

Como se aprecia en el cuadro 1, en el orden de aparición de los animales y sus características se refleja el proceso de la pérdida de la facultad emotiva de los personajes en el cuento. En la primera parte, los pájaros que vuelan ante la escena de violencia, significa un bajo nivel de violencia donde las víctimas posibles todavía podrían escapar y la capacidad débil de sentir de los revolucionarios. En este periodo los hombres muestran actos animalizados como oler, oír, tirarse panza arriba, subir a gatas, quedar agazapados y correr. En la segunda parte del cuento los coyotes aúllan ante la violencia. Los coyotes muestran un nivel medio de la capacidad de sentir, como prediciendo aún más 
resultados trágicos. En esta parte podemos confirmar que la capacidad emotiva de la gente es muy débil, ya que no muestran ningún sentimiento hacia la muerte de sus compañeros que han descubierto como pilas de muertos, ni ante la desaparición de la Perra tampoco. En la tercera parte la presencia de los toros significa la parálisis de la facultad de sentir entre los personajes. No podemos detectar ninguna reacción ni sentimiento en estos animales ante la violencia. Desde las conductas de los actores, como destazar y despellejar toros, incendiar, asolar al pueblo, jugar al toro, descarrilar el tren con los huesos de las vacas y robar mujeres, podemos percibir que los revolucionarios se encuentran en una fase de extrema violencia sin ninguna capacidad de sentir felicidad, tristeza ni culpabilidad.

Además, cuando los hombres de Zamora miran a los "hombres pialados" que "caminaban sobre sus manos", o a los que "se les habían caído las manos y traían descolgada la cabeza", el narrador solo dice que junto con otros "los miramos pasar" y que el espectáculo les "dio gusto" (p. 77). Y no sólo ello, también prenden fuego al llano y queman el maíz, los potreros, los cañaverales. Esta descripción muestra que los sujetos de la tropa de Pedro Zamora ya no sentían nada ante los muertos o la crueldad de sus hechos. Cuanto más, ellos pensaban que el fuego sobre los potreros "se veía muy bonito" (p. 77), sin ningún sentido de culpabilidad. En esta parte, el Llano, que un momento atrás estaba en paz, se cambia por el Llano amenazado por el terror, y en el final queda como "el llano vacío" (p. 80), ya con minúscula, debido al fuego que ha acabado con todo.

En resumen, el narrador y los hombres en el cuento no muestran ningún sentimiento sobre la circunstancia social: los muertos y sus fechorías. Como se afirma en la propuesta teórica de Nussbaum (1996) sobre el rol social de emoción, la facultad emotiva funciona como un tipo de razonamiento o pensamiento y enlaza los individuos a la sociedad, según hemos citado con anterioridad. En el cuento El Llano en llamas la desaparición de la facultad de sentir elimina también la capacidad de pensar de los hombres, permitiendo la ejecución de actos brutales sin culpabilidad ni responsabilidad. El cese de la sensación, como explicaremos en los párrafos siguientes, lleva a la tragedia mayor de dejar atrás las causas de la repetición de dichas tragedias. 


\section{Las tragedias concomitantes: la circulación de la tragedia}

Aunque el texto original del corrido popular trata de "La Perra" que es la Perra, personaje cuya existencia está comprobada en la historia, ${ }^{11}$ en el epígrafe del cuento El Llano en llamas, Rulfo propone un nuevo sentido de "la perra" al poner las primeras letras del artículo y del sustantivo con minúsculas. De esta manera, Rulfo induce a la paradoja de pensar que las letras bajas de las dos líneas tendrían un sentido más extenso. Como el corrido ya menciona a la perra y los perritos "en general", las inferencias que se refieren a las circunstancias de México en la época son lógicas y previsibles, independientemente de la persona con el apelativo de La Perra que participó en la Revolución Mexicana. Por eso, revisaremos la implicación de la circulación de la tragedia, debido al cese de la facultad emocional, a partir del sentido del epígrafe sobre la perra que desaparece, dejando a los perritos.

Si "la perra" significa la generación antecedente y "los perritos" las generaciones siguientes, las letras del corrido insinúan que dos tragedias circulan a pesar de los cambios de generación. Primero, en el nivel de familia, el futuro de la generación de los hijos es oscuro debido a la ausencia de jefes de familia responsables. Segundo, en el nivel de la nación entera, la violencia social y la desconfianza provocadas por los errores de la generación anterior y la incompetencia del gobierno. Esas causas de la repetición de la tragedia, los padres irresponsables y el abandono del esfuerzo por comprender a los demás, son los resultados del cese de la capacidad emotiva de la gente.

\section{La circulación de la tragedia en el nivel de familia}

En El Llano en llamas aparecen varios tipos de familia. La de la Perra y los Joseses, la familia de donde provenía la mujer del narrador-personaje, el Pichón, y que forma el Pichón después de salir de la cárcel. El punto común de las familias en el cuento es la ausencia del padre responsable y ejemplar. Los padres no pudieron proteger a los miembros de la familia, o faltaron en la capacidad o la voluntad de mantenerlas. Ante la ausencia de sentimientos

11. 'Este corrido, titulado 'De la Perra valiente', compuesto en 1916, celebra las hazañas de Saturnino la Perra quien, según dice el corrido, luchó junto a Pedro Zamora, alistado en las tropas de Pancho Villa y a quien un tal capitán Téllez, al servicio de Obregón, mandó fusilar el día 4 de marzo de 1916, a las seis de la mañana" (Cros, 1998: 215). 
como ansiedad o cuidado para sus hijos, esos padres irresponsables e incapaces resultan causantes de la tragedia de su propia generación (la perra) que se repetirá en la generación de los hijos (los perritos).

Primero, según la relación de padre e hijo en la familia de la Perra, la Perra era valiente en la guerra pero era indiferente, sin nada de emoción para sus hijos, y en el cuento no se le da la oportunidad de demostrar la voluntad o responsabilidad para protegerlos. La Perra desparece pronto del relato - "Se lo han de haber llevado para enseñárselo al gobierno” (p. 74)—y los Joseses, que serían los perritos, se quedan sin su padre y con miedo. Los Joseses se aquietan sólo después de que Pedro Zamora les grita: “ $¡ Y a$ sé que falta su padre, pero aguántense, aguántense tantito!” (p. 73). En estas condiciones, los hijos que se quedan tendrían mucha posibilidad de repetir la vida de su padre que ha muerto víctima de la violencia. La tragedia de la generación de los padres se repetiría igualmente en la generación de los hijos.

Las familias que aparecen en el relato también se presentan con padres desprovistos de cualquier sentimiento para con sus hijos. Cuando la mujer de el Pichón sufre de estupro, el padre pierde la vida sin poder proteger a su hija. La mujer queda como víctima de la situación trágica, sin ninguna protección ofrecida por parte de su familia. Aunque ella con fortaleza reconoce a su marido y cría a su hijo confiando en que "no es ningún bandido ni ningún asesino" y que "es gente buena" (p. 87), la posibilidad de repetir la tragedia en la generación de los hijos no se elimina. A partir de la descripción del narrador sobre su hijo, cuando dice que "era igualito a mí [a él] y con algo de maldad en la mirada" (p. 87), abre la posibilidad de que la tragedia que el Pichón sufrió como miembro de la tropa de revolucionarios pueda repetirse en la vida de su hijo.

A pesar de la paternidad, el Pichón no muestra ningún sentimiento parental ni voluntad para preparar un mejor futuro para su hijo ni se relata esfuerzo alguno para protegerlo de la tragedia que él mismo sufrió. Desde el personaje de la mujer, se podría presumir un futuro con esperanza, pero la apariencia del hijo semejante a su padre permite la interpretación de que el hijo podría repetir el mismo tipo de vida que su padre en el futuro. De esta manera, estos ejemplos de familias en El Llano en llamas sugieren la posibilidad de que la tragedia y la violencia de la generación de los padres (la perra) podrían circular en la generación de los hijos (los perritos). 


\section{La circulación de la tragedia en el nivel de sociedad}

En el nivel de la sociedad entera, la generación anterior (la perra) asoló e incendió el llano que fue fecundo en acciones brutales, como la Revolución Mexicana o la Guerra Cristera. ${ }^{12}$ Los tiempos posteriores en el llano seco quedan en una situación tal, que es difícil esperar un futuro próspero y abundante. La violencia extrema aparece debido a la actitud indiferente y sin emoción ante los hombres y la sociedad. Los pobladores siguientes (los perritos) que quedan tienen mucha posibilidad de repetir la tragedia brutal de los anteriores. La revolución de la generación anterior, debido a la deformación y degeneración que sufre, queda como el brote de posible violencia y desconfianza en la generación próxima, y los sucesores no podrían escapar a la circulación de dicha tragedia.

Los revolucionarios que aparecen en el cuento incendiaron el Llano, mataron, se dañaron unos a otros y perjudicaron a gente inocente, a causa de las guerras contra las tropas del gobierno. Este proceso se explica con la narración indiferente de el Pichón, un miembro típico de la tropa rebelde. El tono de la narración de este personaje, que está privado de toda emoción, revela que los revolucionarios tampoco sentían ningún sentimiento de culpabilidad al cometer hechos violentos, ya fueran raptos o maltratos en general. Además, en esta situación faltaría el mecanismo a nivel nacional para corregir las deformaciones de la sociedad, lo que significa que la sociedad en general ha cesado de utilizar la facultad emotiva. Cuando el Pichón va a la cárcel, el gobierno muestra su incapacidad porque no puede reconocer todas las culpas del malhechor. El gobierno no supo que el Pichón había andando con Pedro Zamora ("Yo salí de la cárcel hace tres años. Me castigaron allí por muchos delitos; pero no porque hubiera andado con Pedro Zamora. Eso no lo supieron ellos". p. 86). Como en el cuento no hay ningún mecanismo con autoridad suficiente como para eliminar los orígenes de la violencia en el nivel

12. Carlos Fernández-Liria (2001) reflexiona sobre el caso de los indígenas de Chiapas y, especialmente en el segundo capítulo de la primera parte de su libro donde expone los resultados de una investigación etnográfica realizada entre 1991 y 1993, llega a la conclusión de cómo los métodos de dominación a los que se han visto sometidos son parecidos, ya sea por parte de sus propias autoridades nativas o del gobierno estatal y local, en términos de la corrupción y de la manipulación de sus tradiciones. El autor habla de una tragedia circular, intemporal e inevitable, como la del destino que enfrentaban los personajes griegos. 
de la sociedad, y como los miembros de la sociedad no se arrepienten de sus culpas del pasado, es posible que la tragedia se repita y permanezca circulando.

Además, la violencia social extrema no sólo hace a la gente indiferente ante los incidentes violentos, sino que también queda el resentimiento y la desconfianza entre la población misma. Aunque la generación que comenzó la violencia en el primer momento haya desaparecido, quedan las semillas de otras brutalidades y venganzas en forma de hostilidad, todo lo cual insinúa de nuevo otra circulación de la tragedia. Por ejemplo, el Pichón relata: "hubiéramos ido de buena gana a decirle a alguien que ya no éramos gente de pleito y que nos dejaran estar en paz; [...] lo único que habíamos logrado era agenciarnos enemigos" (p. 85). De esta afirmación se deduce que lo único que los revolucionarios hubieron logrado fue la creación de enemigos, sin ningún sentimiento ni ningún esfuerzo de empatía entre ellos. Por otra parte, la desconfianza que se fue sumando durante la guerra agrandó la desconfianza de la gente en general. Por ejemplo, cuando el Pichón encuentra a su mujer esperándolo al salir de la cárcel, dice: "Yo entonces pensé que me esperaba para matarme" (p. 86).

La actitud suspicaz del narrador muestra que la gente ya no podía tener confianza en los otros después de la Revolución. De este modo, en el nivel de la sociedad entera, el antagonismo, la violencia y la desconfianza quedan como semillas de futuras violencias y desconfianzas, quedando abierta la posibilidad de otros conflictos a pesar de la desaparición del problema inicial $y$, al final, quedando configurado un espacio para la circulación de la tragedia, como se puede apreciar en el cuadro siguiente:

\section{Cuadro 2}

El cese de facultad emotiva y la circulación de la tragedia

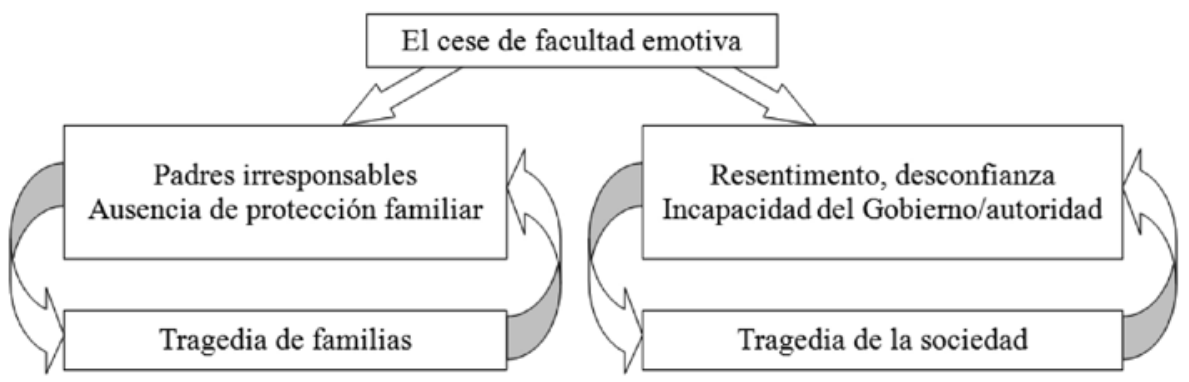

Fuente: elaboración propia. 
El cese de la facultad emotiva de los miembros de una sociedad deriva en la circulación de dos tipos de tragedia. Como se aprecia en el cuadro 2, primero, sin la facultad de sentir afecto, tristeza o compasión por los miembros de su familia, la gente pierde la capacidad de responsabilidad sobre su familia, de manera que los hijos no reciben ninguna protección. De este modo los hijos tienen mucha posibilidad de repetir la vida de sufrimiento de sus padres. Segundo, la parálisis del sentimiento lleva a la gente a ser indiferente ante los dolores de los demás y a no sentir ninguna culpabilidad sobre sus actos perjudiciales o violentos. Los actos que dañan a otros crean el resentimiento y la desconfianza entre los miembros de una sociedad. Sin la facultad de sentir, ni al gobierno ni a cualquier otra autoridad les importa el orden de la sociedad, lo que trae como consecuencia su incapacidad para regir y regular la sociedad. En consecuencia, la siguiente generación queda en una situación con mucha probabilidad de repetir el conflicto interno que tanto daño causó a sus predecesores.

\section{Conclusión}

La facultad de sentir, que a menudo está considerada como irreflexiva o hasta irracional, más bien es motivadora y fundadora de un pensamiento sensible y de actos responsables. Gracias a emociones como la ansiedad, la inquietud, la compasión o la empatía, la gente simpatiza con los demás y se preocupa por los intereses de otros. Cuando la gente deja de sentir la emoción básica, como la tristeza o el terror, puede cometer actos destructivos sin ningún remordimiento, de forma animalizada, con la circulación de la tragedia correspondiente, tal y como se representa en el cuento El Llano en llamas.

En el nivel de familia y de sociedad, como la generación anterior (la perra) falla en el esfuerzo y la responsabilidad deseables para construir los fundamentos del futuro de sus familias y de su país, los sucesores (los perritos) quedan expuestos a esta situación árida que podría ser el comienzo de otra tragedia. Esta incapacidad e irresponsabilidad son consecuencias de la supresión de la facultad emotiva. La desaparición de la facultad de sentir y la concomitante agravación de la violencia significan que la emoción es una facultad conductiva y necesaria para evitar la demolición de una sociedad.

A través de la actitud del narrador - "el Pichón agachando su cabeza en frente de su hijo" (p. 87) al final del cuento-, el autor critica y denuncia que la generación anterior que fue irresponsable tenía que haberse sentido culpable 
de quienes quedaron atrapados en la circulación de la tragedia, y Rulfo también nos propone una lectura de que la gente de estos tiempos contemporáneos, con el conocimiento del riesgo del cese de sentir sobre los otros y sobre la sociedad, debe ser responsable de que sus vestigios quedarán vigentes en el futuro. Como resume Fernández-Liria en entrevista:

\begin{abstract}
El fenómeno más inquietante del siglo xx, desde Auschwitz al día de hoy, es la tranquilidad de conciencia occidental. Se trata de un verdadero enigma ético, cómo es posible vivir en un mundo como éste con la conciencia tranquila [...] Toda Alemania sabía que existían campos de concentración y, sin embargo, toda Alemania lo consideró pura rutina. Todo un pueblo había colapsado moralmente (García del Campo, 2006: 24).
\end{abstract}

Y en términos de nuestro corpus de estudio, El Pichón parece mostrar finalmente su capacidad de sentir remordimiento ante su hijo y su mujer, pero el cuento ha terminado y no tiene posibilidad de demostrarlo con hechos ni de remontar el pasado.

\title{
Referencias bibliográficas
}

Berlin, Isaiah (1979), Against the Current: Essays in the History of Ideas, Londres: Hogarth Press.

Cros, Edmond (1998), "Desde la epopeya villista al sinarquismo: Análisis sociocrítico de El Llano en llamas", Revista Canadiense de Estudios Hispánicos, 22(2), pp. 215-224.

Damásio, Antonio C. R. (1999), The Feeling of What Happens: Body and Emotion in the Making of Consciousness, Nueva York: Harcourt Brace.

Fernández-Liria, Carlos (2001), Geometría y tragedia. El uso público de la palabra en la sociedad moderna, Navarra: Hiru.

García del Campo, Juan Pedro (2006), "Pensar, investigar... y hacerlo bien", Youkali. Revista crítica de las artes y el pensamiento, núm. 1, pp. 19-32.

Jacobs, Lawrence R., y Shapiro, Robert Y. (2011), "Informational Interdependence: Public Opinion and the Media in the New Communications Era”, en Lawrence R. Jacobs y Robert Y. Shapiro (eds.), Oxford Handbook of American Public Opinion and Media, Nueva York: Oxford University Press, pp. 384-401.

LeDoux, Joseph E. (1996), The Emotional Brain: The Mysterious Underpinnings of Emotional Life, Nueva York: Simon \& Schuster. 
Macías de Yoon, Claudia (2013), "Topografía y naturaleza, una lectura simbólica de El Llano en llamas”, Estudios Hispánicos, núm. 68, pp. 217-241.

Marcus, George E. (2002), The Sentimental Citizen: Emotion in Democratic Politics, University Park: Pennsylvania State University.

Marcus, George E., y Mackuen, Michael B. (1993), “Anxiety, Enthusiasm, and the Vote: The Emotional Underpinnings of Learning and Involvement During Presidential Campaigns", The American Political Science Review, 87(3), pp. 672-685.

Mendoza, Vicente T. (1954), El corrido mexicano, México: Fondo de Cultura Económica.

Nussbaum, Martha C. (1996), "Compassion: The Basic Social Emotion", Social Philosophy and Policy, 13(1), pp. 27-58.

Real Academia Española (2001), Diccionario de la lengua española, $22^{\mathrm{a}}$ edición, Web.

Rolls, Edmund T. (1999), The Brain and Emotion, Nueva York: Oxford University Press.

Rulfo, Juan (2005 [1953]), “El Llano en llamas”, en El Llano en llamas, México: Fundación Juan Rulfo/Editorial RM, pp. 69-87.

Valentino, Nicholas A., Hutchings, Vincent L., Banks, Antoine J., y Davis, Anne K. (2008), "Is a Worried Citizen a Good Citizen? Emotions, Political Information Seeking, and Learning via the Internet", Political Psychology, 29(2), pp. 247-273.

Westen, Drew (2008), The Political Brain: The Role of Emotion in Deciding the Fate of the Nation, Nueva York: Public Affairs. 


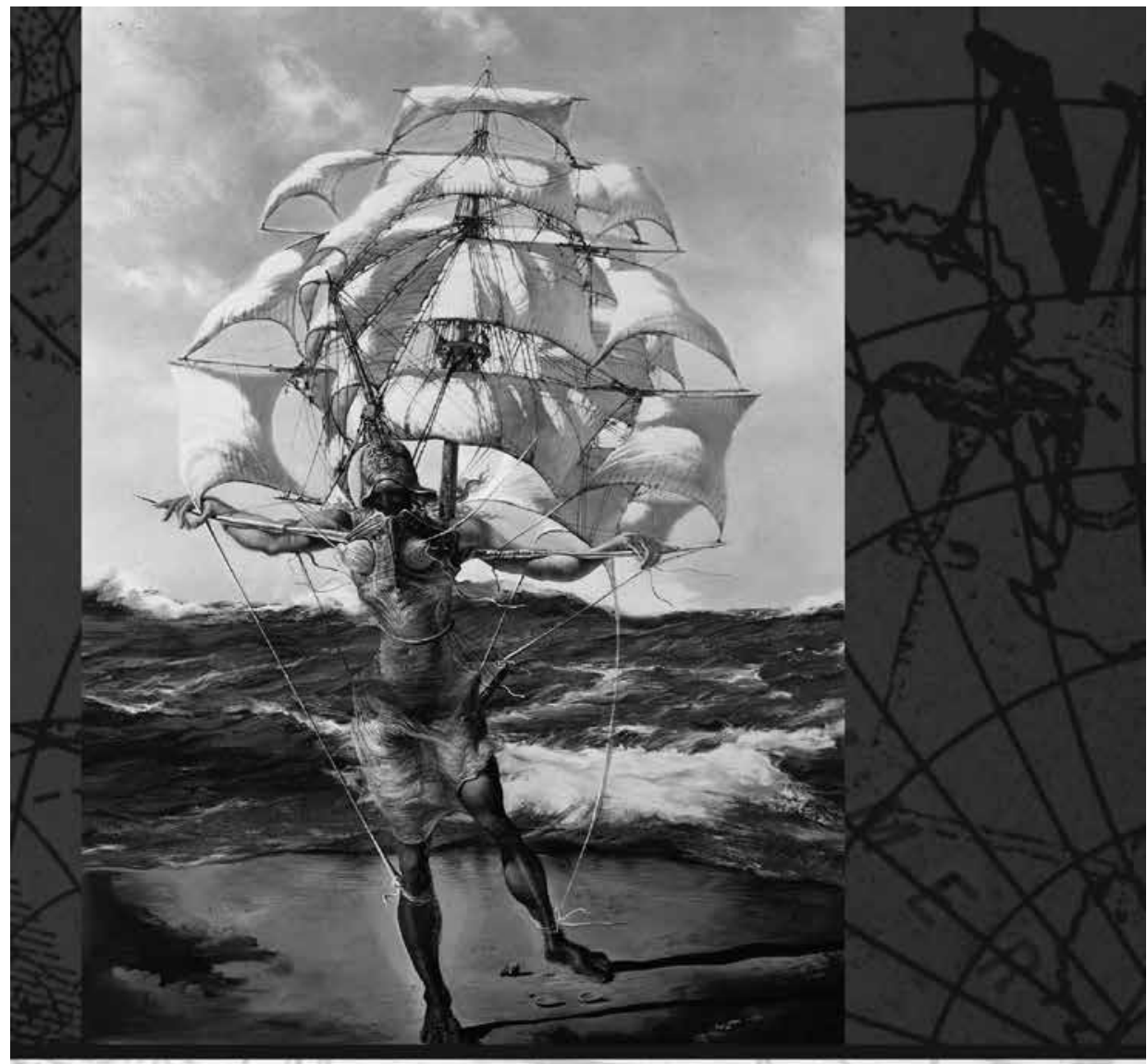

\section{Navigating the Spanish Lake}

The Pacific in the Iberian World, 1521-1898

RAINER F. BUSCHMANN

EDWARD R. SLACK JR.

JAMES B. TUELLER 